\title{
CFD Modeling Of Turbulence in Channels of Plate Heat Exchangers
}

\author{
Dragan Mandic \\ JKP Belgrade Power Plants \\ Savski nasip 11, Belgrade, Serbia \\ dragan.mandic@bgdel.rs
}

\begin{abstract}
The subject of this paper is turbulence modeling of fluid flow in channels of plate heat exchangers for heating domestic hot water in heating substation in Belgrade. For testing of turbulence phenomena in the channels, this paper uses the standard K- $\varepsilon$ model of turbulence. It is of particular importance that in this paper the modeling is made for different flow rates of fluids through channels, adopted in boundary conditions. The rate of flow in the input area of the channels was taken as the assumed average values of $0.01 \mathrm{~m} /$ $\mathrm{sec}$, and $0.1 \mathrm{~m} / \mathrm{sec}$, which presupposed minimum and maximum values based on the measured values of these fluid velocities in the heat substations. On the basis of these assumed speeds, the values of the exchanged kinetic energy and the character of the change in the intensity of the projections of these velocities in the direction of all three axes are obtained. On the basis of these projections, we can determine the unsteadiness of the velocity and the return currents along these channels and in their contour surfaces as well as the "dead spots" in which there is no movement of the fluid.

This work presents the calculated values of the Reynolds number of the streamline for the assumption velocity of fluid in channels. These phenomena can cause different problems in the transmission of heat and dirt in the channels of the plate heat exchangers where there is no circulation. Therefore, the obtained results can serve as a basis for dimensioning and selection of heat exchangers as well as for determining their optimal working conditions.
\end{abstract}

Keywords: Plate Heat Exchangers, Fluid Flow, Channels.

\section{Introduction}

Distribution and preparation of sanitary hot water in Belgrade takes place 24 hours a day [1,8], but with very different intensity during the day. The highest consumption of this water in the apartments is in the early morning and evening hours, as shown in the following diagram:

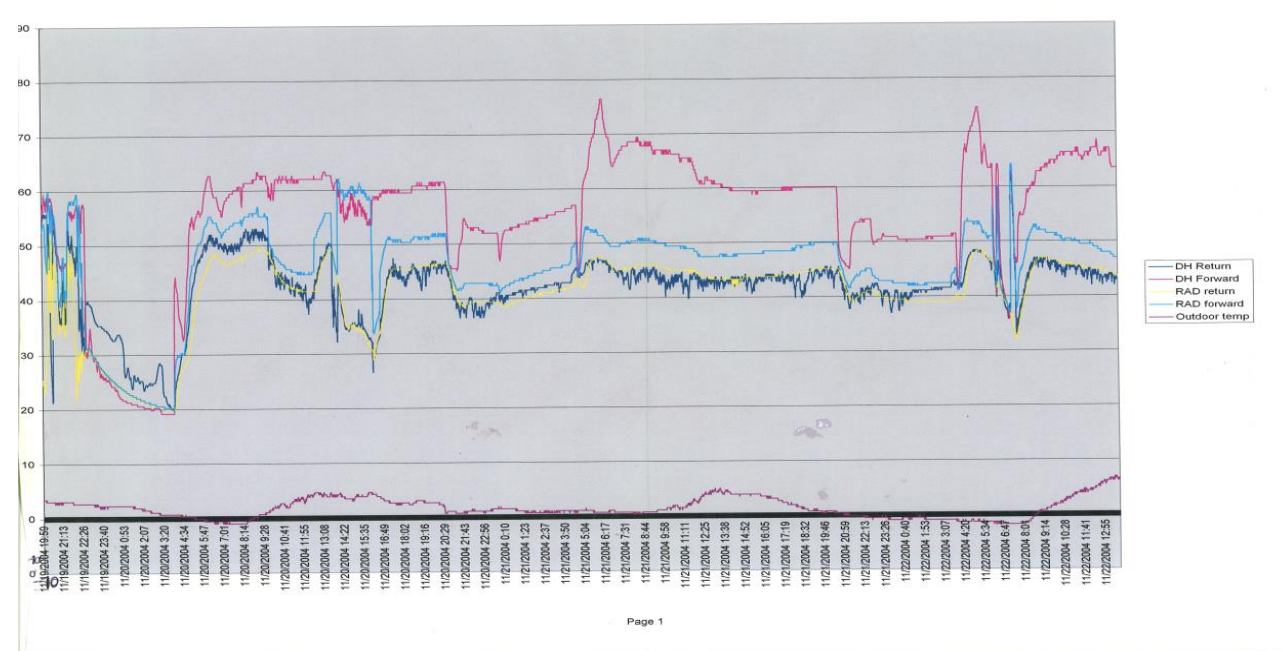

Fig. 1: Diagram of consumption of sanitary hot water in Belgrade.

From the diagrams it can be seen that in these intervals the consumption of this water is multiplying. Measurements of fluid flow also show that the existing control equipment must react in several ways over a period of 1 second, causing 
hydraulic impacts in the heat substations and the complete heating system. Also, from the diagram it can be seen that in the night hours there is practically no consumption of sanitary hot water.

\subsection{The k-epsilon Model in ANSYS CFX}

$\mathrm{k}$ is the turbulence kinetic energy[7] and is defined as the variance of the fluctuations in velocity. It has dimensions of $\left(\mathrm{m}^{2} / \mathrm{sec}^{2}\right)$; for example, $\mathrm{m}^{2} / \mathrm{s}^{2}$ is the turbulence eddy dissipation (the rate at which the velocity fluctuations dissipate), and has dimensions of per unit time $\left(\mathrm{m}^{2} / \mathrm{sec}^{3}\right)$.

$$
\begin{gathered}
\rho \frac{\partial\left(\rho_{k}\right)}{\partial t}+\frac{\partial}{\partial x_{j}}\left(\rho U_{j} k\right)=\frac{\partial}{\partial x_{j}}\left[\left(\mu+\frac{\mu_{t}}{\sigma_{k}}\right) \frac{\partial k}{\partial x_{j}}\right]+P_{k}-\rho_{\varepsilon}+P_{k b} \\
\frac{\partial\left(\rho_{\varepsilon}\right)}{\partial t}+\frac{\partial}{\partial x_{j}}\left(\rho U_{j} \varepsilon\right)=\frac{\partial}{\partial x_{j}}\left[\left(\mu+\frac{\mu_{t}}{\sigma_{\varepsilon}}\right) \frac{\partial \varepsilon}{\partial x_{j}}\right]+\frac{\varepsilon}{k}\left(C_{\varepsilon 1} P_{k}-C_{\varepsilon 2} \rho_{\varepsilon}+C_{\varepsilon 1} P_{\epsilon b}\right) \\
P_{k=} \mu_{t}\left(\frac{\partial U_{i}}{\partial x_{j}}+\frac{\partial U_{j}}{\partial x_{i}}\right) \frac{\partial U_{i}}{\partial x_{i}}-\frac{2}{3} \frac{\partial U_{k}}{\partial x_{k}}\left(3 \mu_{t} \frac{\partial U_{k}}{\partial x_{k}}+\rho_{k}\right)
\end{gathered}
$$

\subsection{Reynolds Number in ANSYS CFX[8]}

$$
\mathrm{R}_{\mathrm{e} L}=\frac{\rho U L}{\mu}
$$

where,

$$
\mathrm{L}=\mathrm{x}, \mathrm{d}, \mathrm{d}_{\mathrm{h}} \text {, etc. }
$$

\section{Problem Statement}

CFD modeling was done for individual channels between the profiled plate, whose cross section is shown in the following figures[1,2,3]:

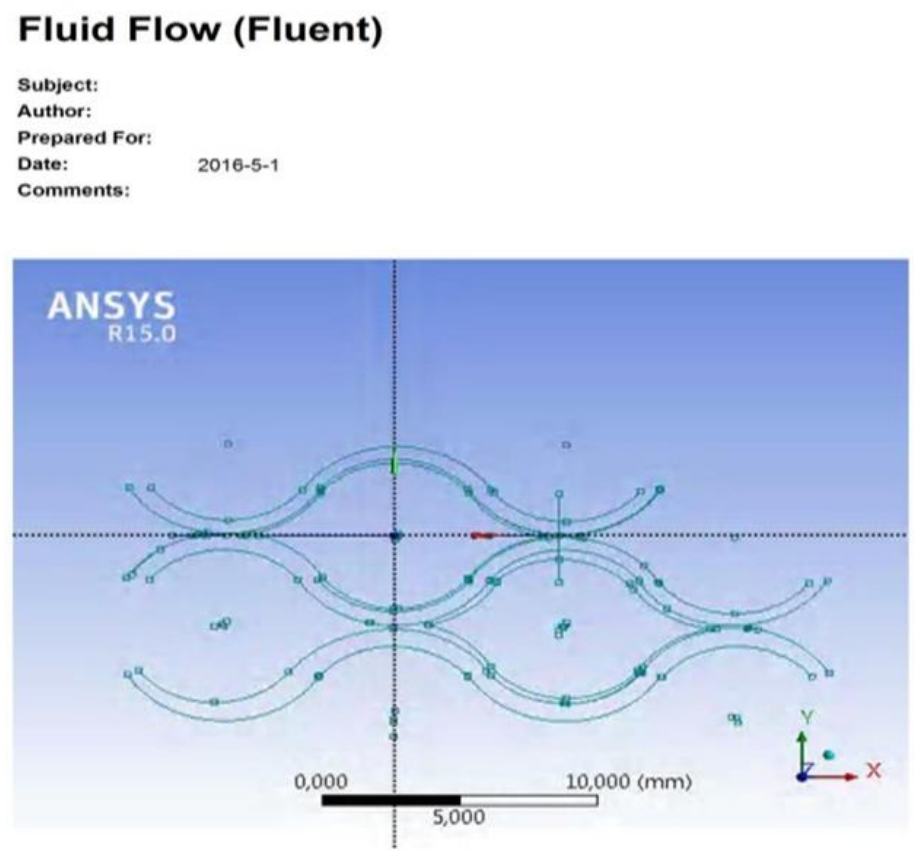

Fig. 2: Channel cross-section. 
The equivalent cross-sectional diameter of the channel is $4.88 \mathrm{~mm}$, and the lengths of shorter and longer diagonals are $4 \mathrm{~mm}$ and $8.2 \mathrm{~mm}[4,5]$.

The individual plate channels are drawn in three-dimensional software ANSYS Design Modeler[7,8], Figure 3.

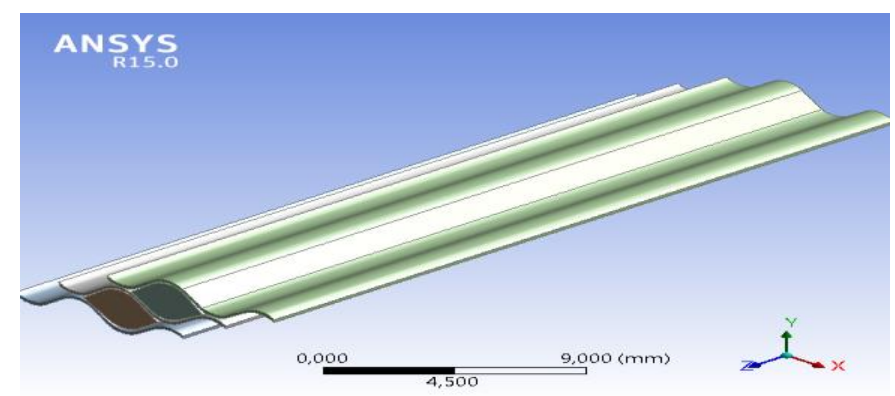

Fig. 3: Individual plate channels.

In these individual plate channels, fluid velocity on both sides of the plate are identical and amounted to $0.01 \mathrm{~m} / \mathrm{sec}$. A numerical network is generated for this panel [8], as shown in the following figure:

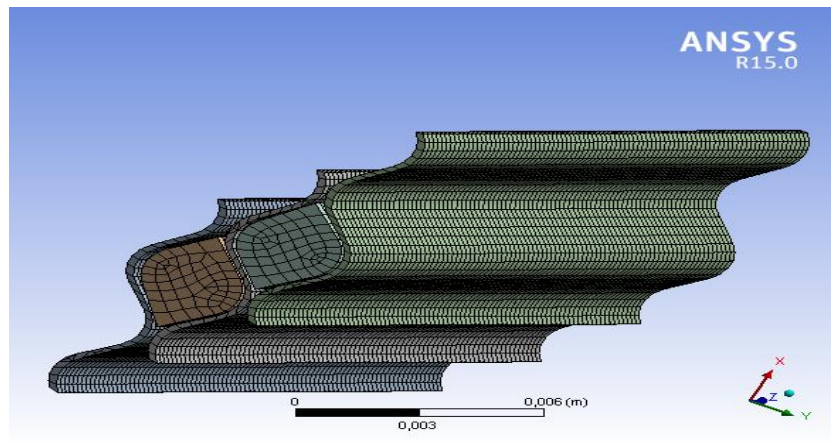

Fig. 4: Generated numerical meshed individual channel plate exchanger.

In the framework of determining the boundary conditions, in addition to the standard boundary conditions stated in this paper, it was necessary to adopt a turbulence flow regime in the channels, and within it a standard K- $\varepsilon$ model of turbulence.

The rate of flow in the input area of the channels had assumption average values of $0.01 \mathrm{~m} / \mathrm{sec}$, and $0.1 \mathrm{~m} / \mathrm{sec}$ [1]. A constant value of static pressure was adopted for both fluids of 500,000 $\mathrm{Pa}$.

The Figures 5a,5b, 6a and $6 \mathrm{~b}$ show the value of fluid flow, projections velocity of fluid flow in the direction of all three axes, the total realized kinetic energy of fluid motion and its dissipation and the total energy exchanged, namely for a number of iterations- until these parameters become closer to their asymptotic values [8]. 


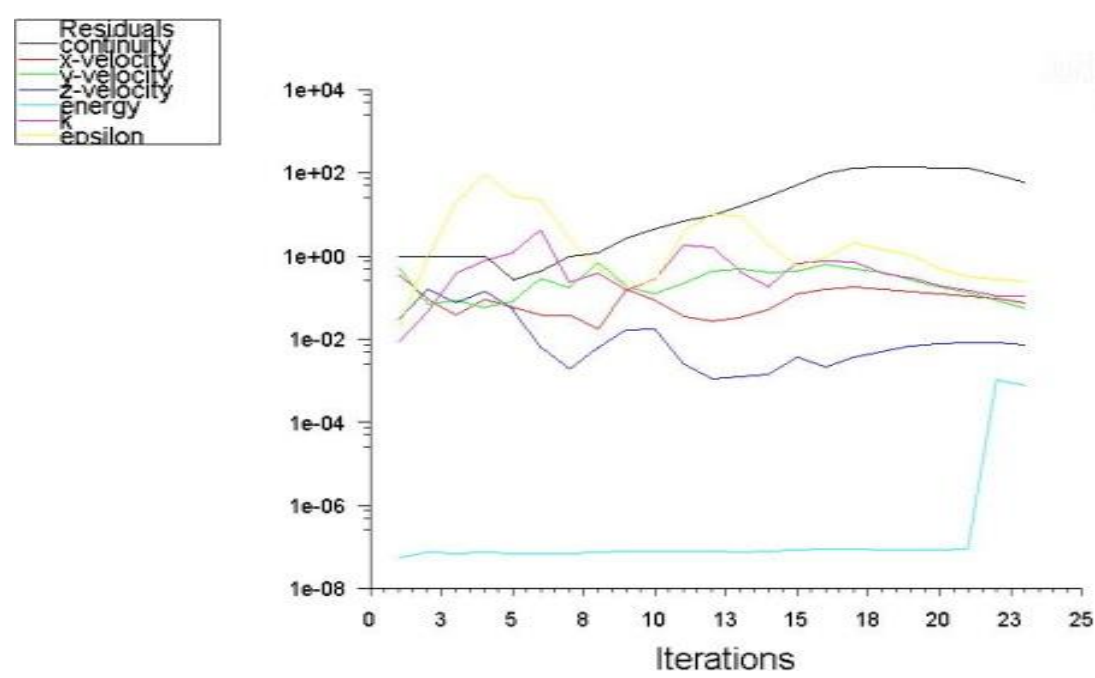

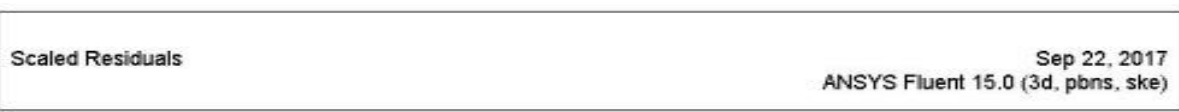

(a)
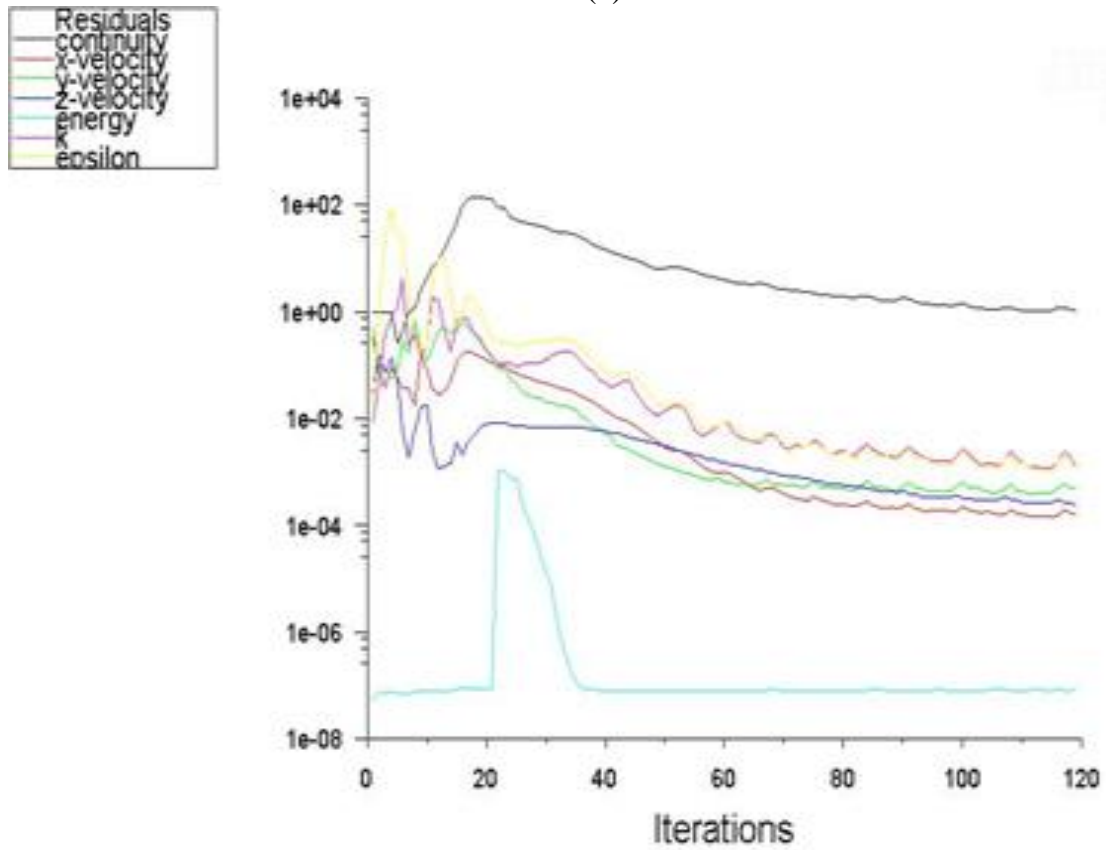

(b)

Fig. 5: Asymptotic values of parameters of fluid flow (in individual channels) between the ruffle plates of the heat exchanger at turbulent flow of fluid at a velocity of $0.01 \mathrm{~m} / \mathrm{sec}$ (a) and at a velocity of $0.1 \mathrm{~m} / \mathrm{sec}(\mathrm{b})$. 

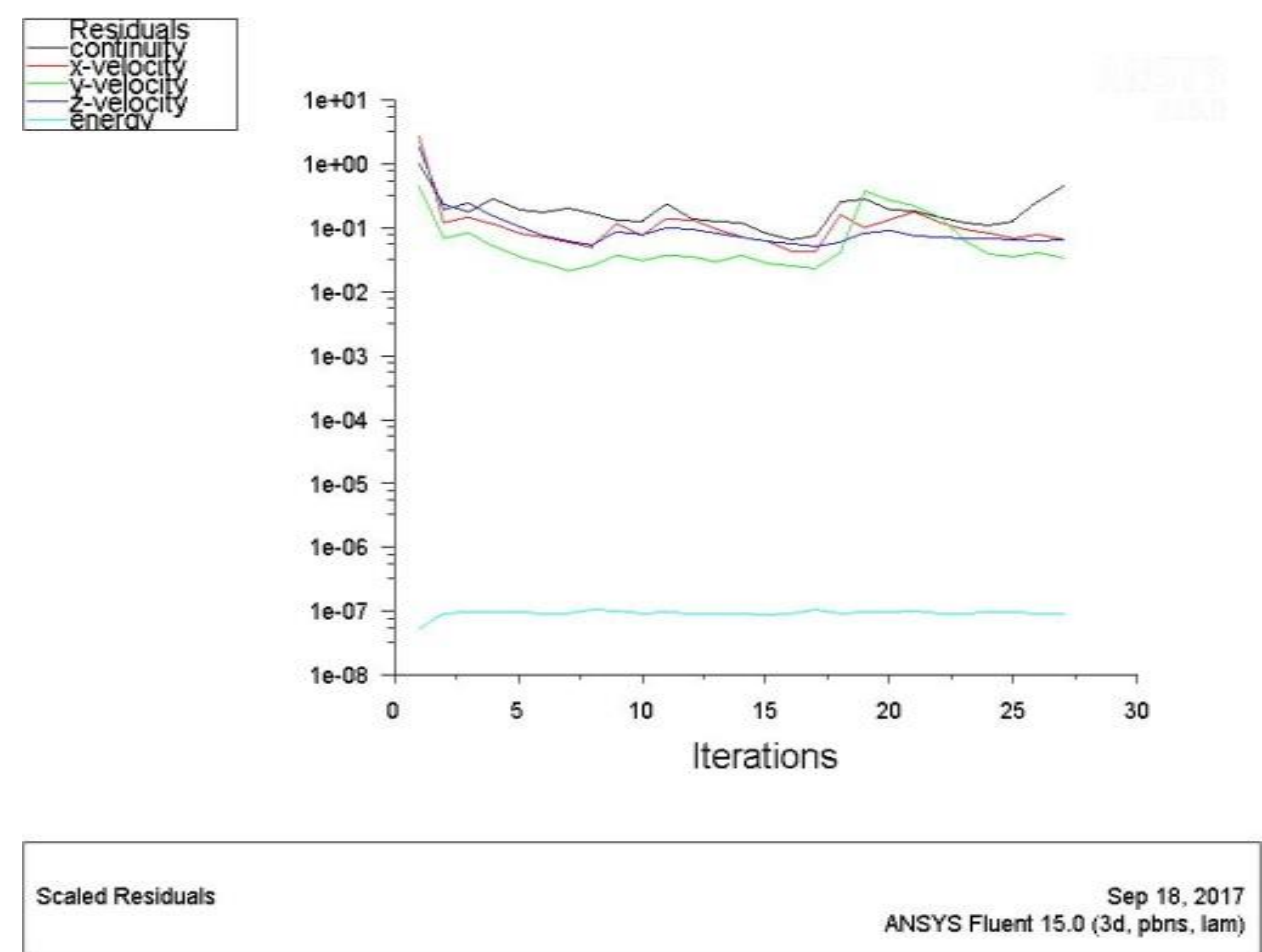

(a)
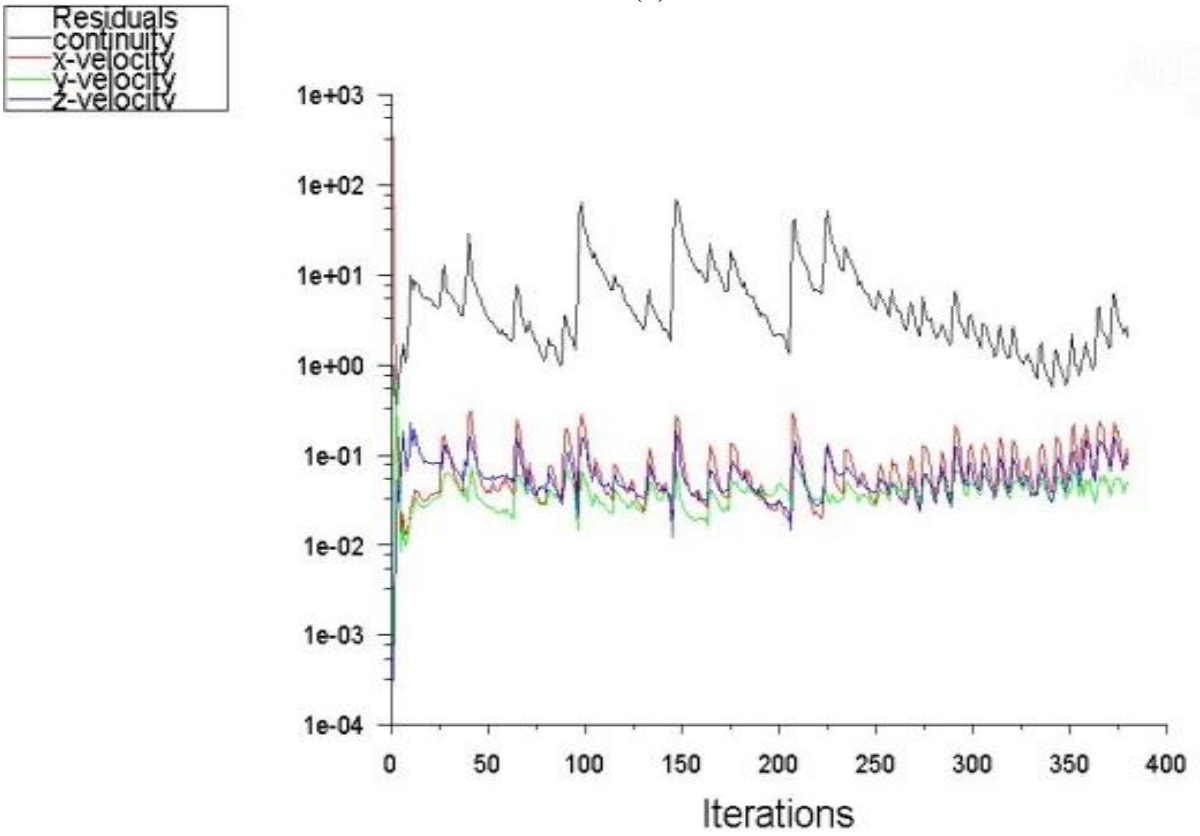

(b)

Fig. 6: Asymptotic values of parameters of fluid flow (in individual channels) between the ruffle plates of the heat exchanger at laminar flow of fluid at a velocity of $0.01 \mathrm{~m} / \mathrm{sec}$ (a) and at a velocity of $0.1 \mathrm{~m} / \mathrm{sec}(\mathrm{b})$. 
Contours of Velocity Magnitude [8] as shown in the following Figures 7 (a and b).

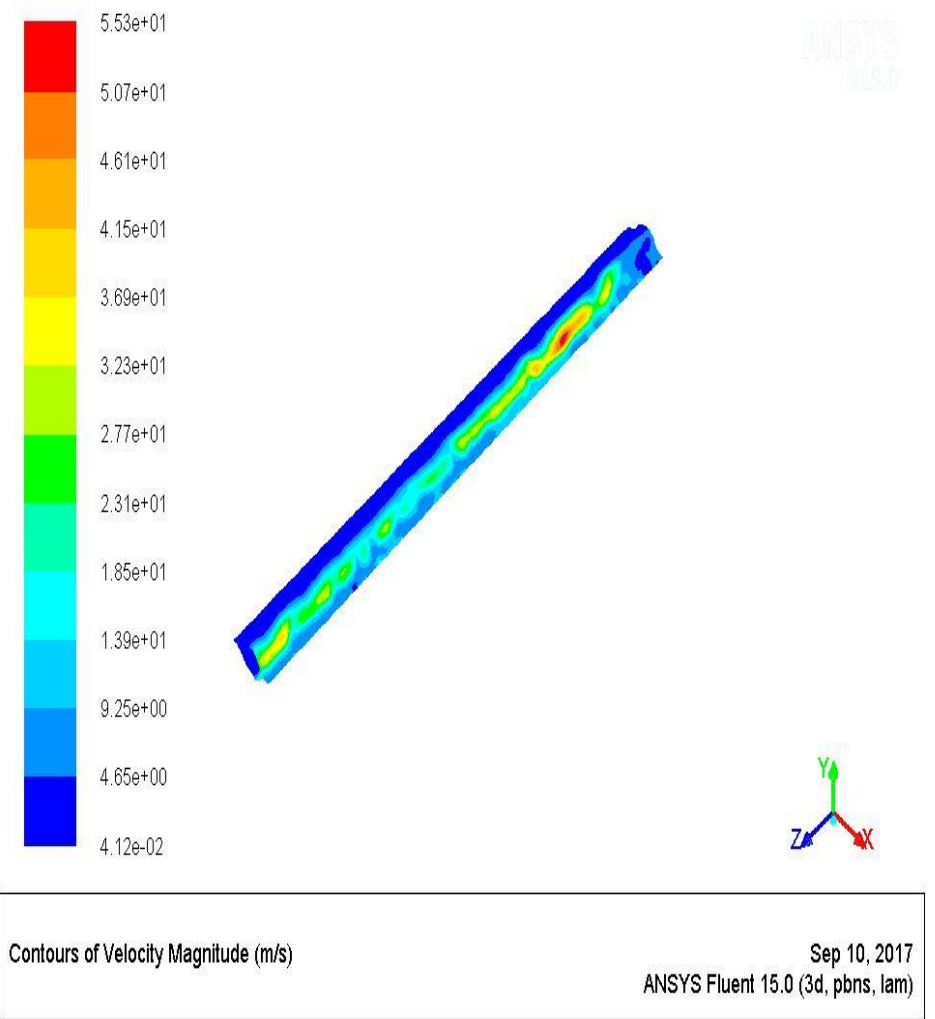

(a)

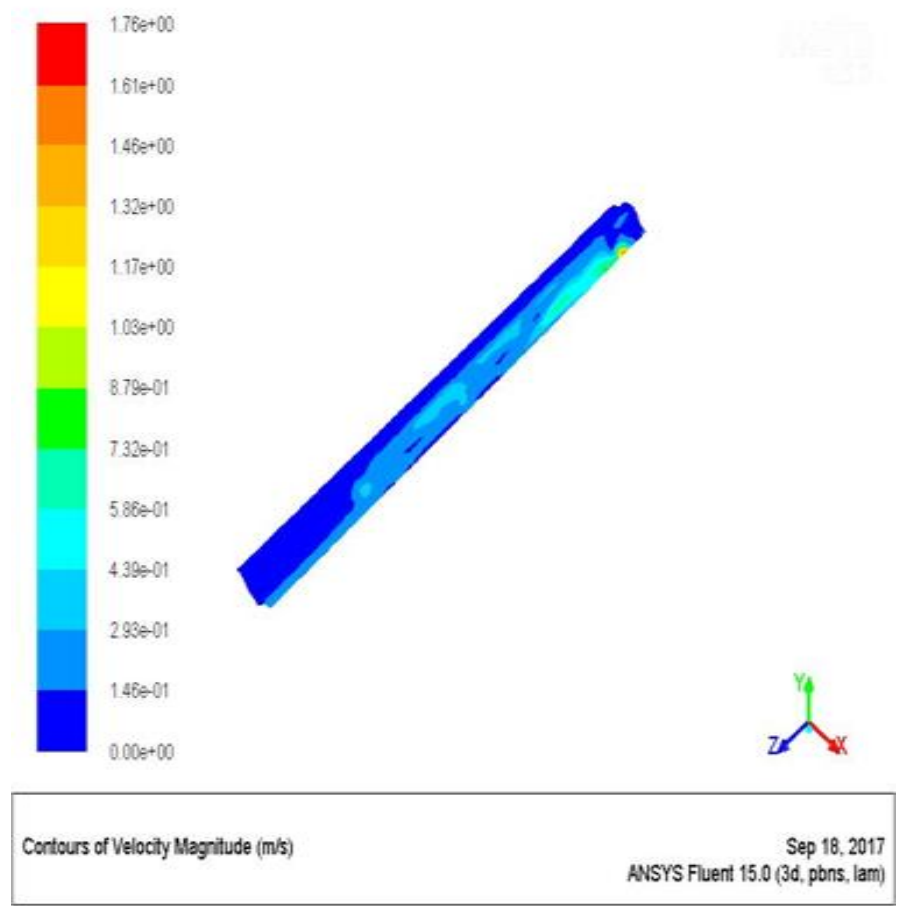

(b)

Fig. 7: Contours of Velocity Magnitude at laminar flow of fluid at a velocity of $0.01 \mathrm{~m} / \mathrm{sec}$ (a) and at a velocity of $0.1 \mathrm{~m} / \mathrm{sec}(\mathrm{b})$. 
Contours of Velocity Magnitude at turbulent flow of fluid at a velocity of $0.01 \mathrm{~m} / \mathrm{sec}$ and at a velocity of $0.1 \mathrm{~m} / \mathrm{sec}$ have a value of zero. Shear stresses between the surface of ruffle plate of heat exchangers and fluid in individual channels $[6,8]$ as shown in the following Figure 8.

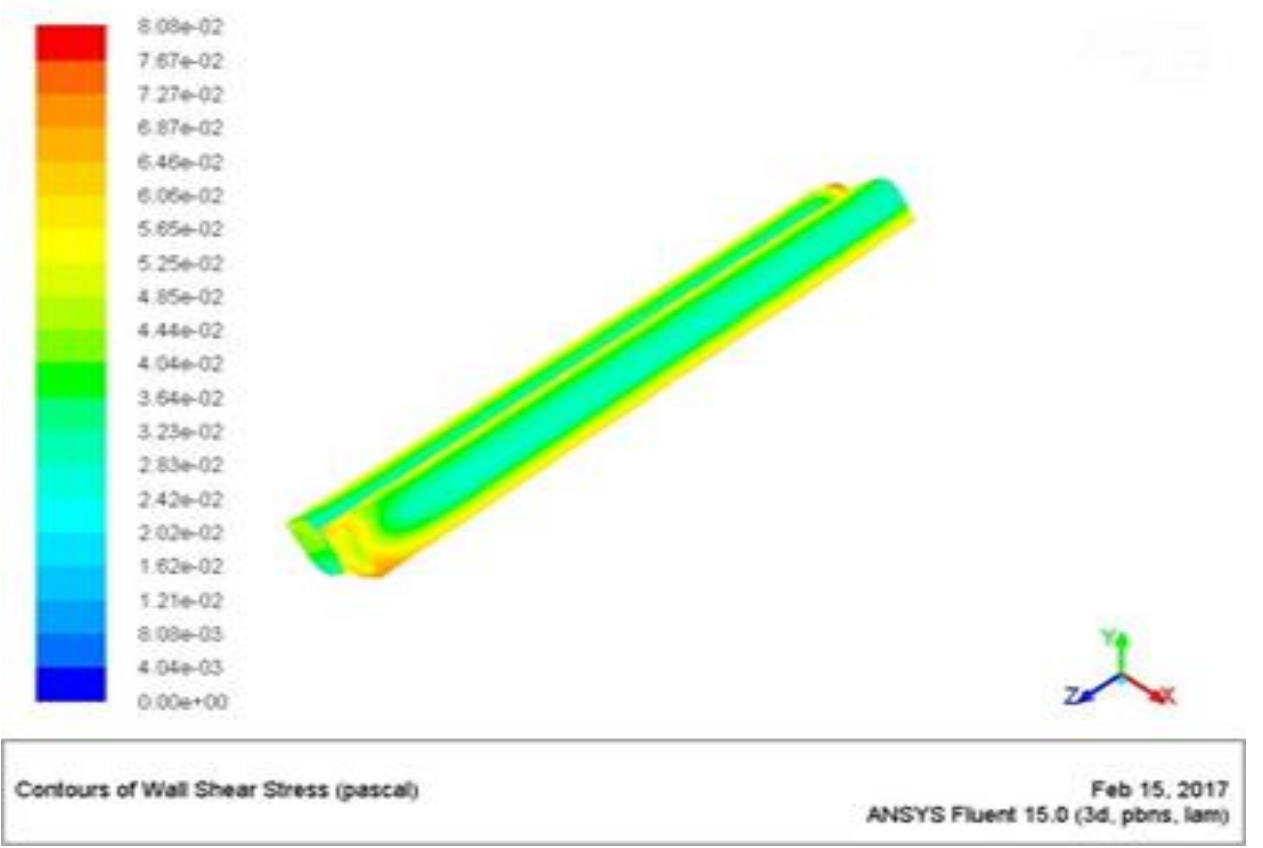

Fig. 8: Shear stresses between the surface of ruffle plate of heat exchangers and fluid in individual channels at laminar flow of fluid at a velocity of $0.01 \mathrm{~m} / \mathrm{sec}$.

Shear stresses at a velocity of $0.1 \mathrm{~m} / \mathrm{sec}$ has a value of zero.

Within the post-proceses research[7], the values of the collecting velocities of fluid flow in the contour surface of the channel as well as the flow velocities in the intersection of the channel were determined, as shown in the following Figure 9 (a and b). 


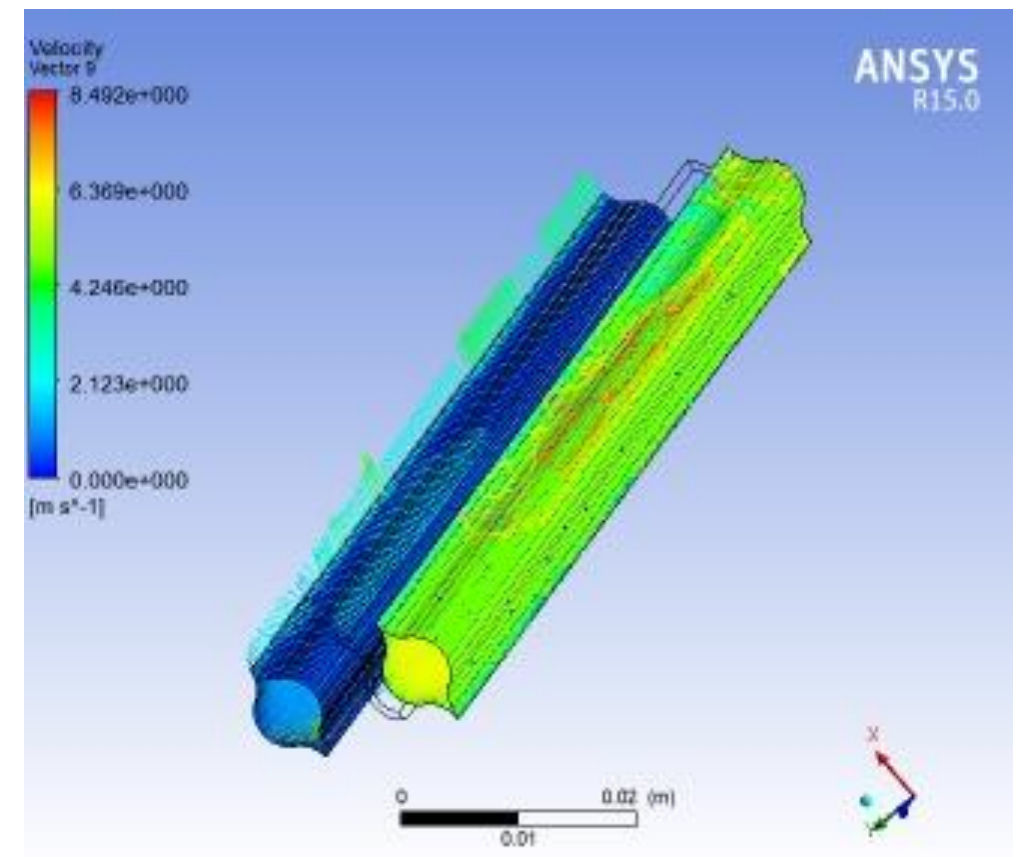

(a)

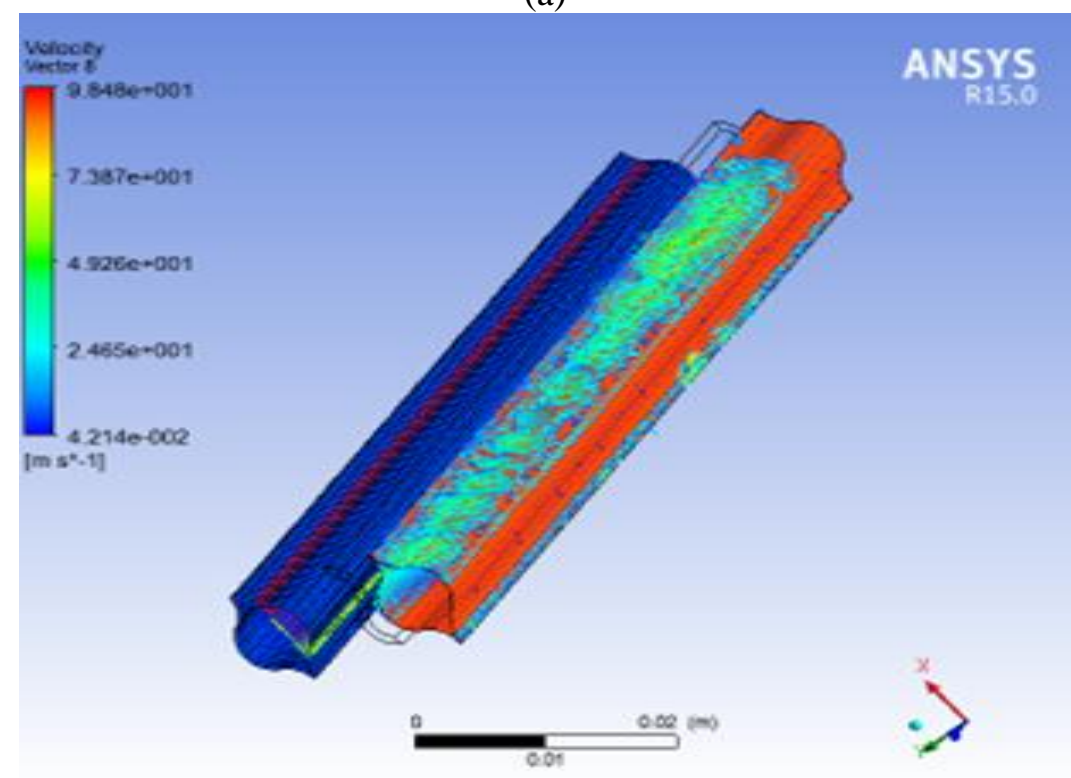

(b)

Fig. 9: Diagram of velocity at laminar flow of fluid at a velocity of $0.01 \mathrm{~m} / \mathrm{sec}$ (a) and at a velocity of $0.1 \mathrm{~m} / \mathrm{sec}$ (b).

Within the post-process research of fluid velocity for turbulent flow in the channels, the speeds of several hundred thousand $\mathrm{m} / \mathrm{sec}$ were obtained. However as such speed is unachievable these results have not been published.

The Contours of Cell Reynolds Number also shown in the following Figure 10. 


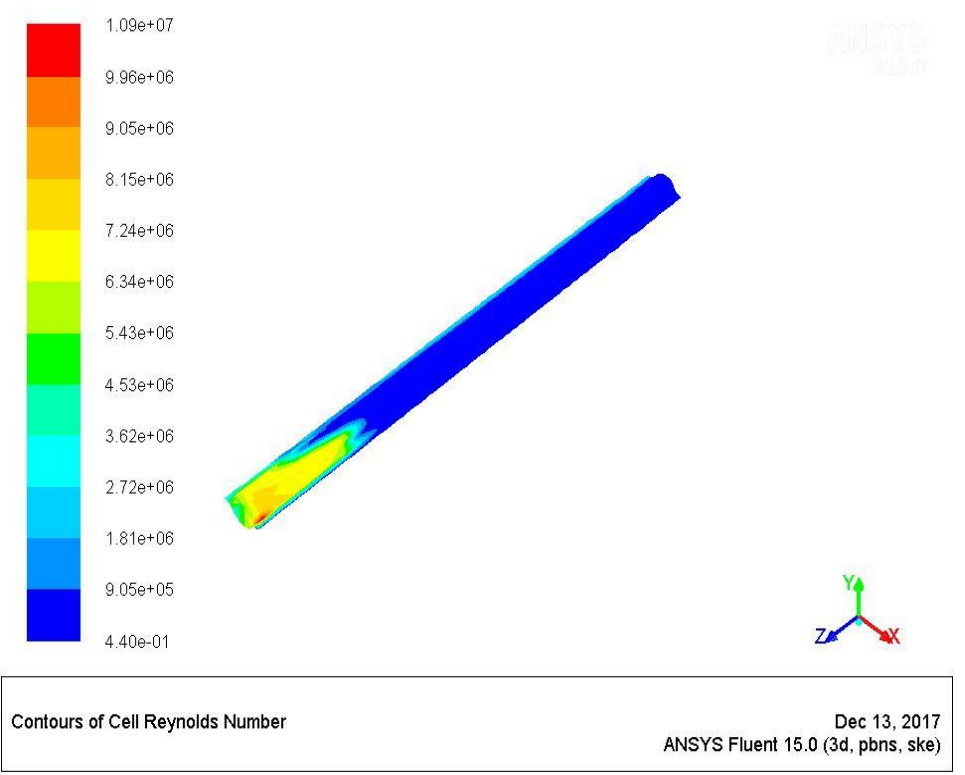

Fig. 10: Diagrams of Contours of Cell Reynolds Number at laminar flow of fluid at a velocity of $0.01 \mathrm{~m} / \mathrm{sec}$.

Contours of Cell Reynolds Number at laminar flow of fluid at a velocity of $0.1 \mathrm{~m} / \mathrm{sec}\left(4.55 \mathrm{e}^{-1}-1.07 \mathrm{e}^{+07}\right)$ have almost the same valueas at velocity of $0.01 \mathrm{~m} / \mathrm{sec}$.

\section{Results and Discussions}

Based on all the research results presented, the following conclusions are drawn:

1. A large unsteadiness of the aggregate flow velocities of the fluid and their projections in the direction of all three axes was established.

2. The existence of "dead zones" in the cross-section of the channel where the plates of exchangers are connected, without any flow of fluid.

3. In the night mode, the consumption of hot water is almost non-existent and then the circulation of the fluid is minimal and practically does not exist

4. At an estimated velocity of $0.1 \mathrm{~m} / \mathrm{sec}$ in the channel intake cross section, the fluid flow velocities in the laminar regime and their projections on all three axes become fluctuating and have the character of trigonometric-sinusoidal changes

5. The intensity of fluid flow velocities is of the order of several hundred thousand $\mathrm{m} / \mathrm{sec}$, which results have been rejected as insufficient

6. The standardized $\mathrm{K}-\varepsilon$ model of turbulence can not be applied to determine the intensity of the flux rate fluctuation in the channels

7. Stratification in the channels is laminar, due to which the values of the tangential stresses on the channel plates are extremely small

8. Contours of Cell Reynolds Number at laminar flow of fluid at a velocity of $0.1 \mathrm{~m} / \mathrm{sec}$ and $0.01 \mathrm{~m} / \mathrm{sec}$ have almost the same value.

\section{Conclusion}

The established laminar flow of fluids in the channels and the existence of dead zones imposes the need for introducing new project procedures for the selection of these channels, considering the assumed accumulated values of the speeds in the inlet channel crossings $(0.01 \mathrm{~m} / \mathrm{sec}$ and $0.1 \mathrm{~m} / \mathrm{sec})$.

The design procedure for the selection of the passage of the fluid should take into account the fact that the surface of the channels in the area of the "dead zone" is seeping off - at the point of connection of the two boards of the exchanger, resulting in a drop in the heat function of the exchanger. 
CFD modeling of turbulent phenomena in plate heat exchanger channels indicates the necessity of its application in maintaining the thermal function of these devices during the period of exploitation.

\section{Nomenclature}

$-C_{\varepsilon 1},-, \mathrm{k}-\varepsilon$ turbulence model constant,

$-C_{\varepsilon 2},-, \mathrm{k}-\varepsilon$ turbulence model constant,

$-\sigma_{\mathrm{k}},-$, turbulence model constant for the k equation,

$-\sigma_{\varepsilon},-, \mathrm{k}-\varepsilon$ turbulence model constant,

$-\rho_{k}, \mathrm{~kg} / \mathrm{m}^{3}$, density for the $\mathrm{k}$ equation

$-\rho_{\varepsilon}, \mathrm{kg} / \mathrm{m}^{3}$, density for the $\varepsilon$ turbulence dissipation rate equation,

$-U_{j}, \mathrm{~m} / \mathrm{sec}$, vector of velocity,

$-k,-$, Von Korman constant,

$-\varepsilon, \mathrm{m}^{2} / \mathrm{sec}^{3}$, turbulence dissipation rate,

$-\mu, \mathrm{kg} / \mathrm{m} \mathrm{sec}$, molecular (dynamic) viscosity,

$-\mu_{t}, \mathrm{~kg} / \mathrm{m}$ sec, turbulent viscosity.

$-P_{k b}, \mathrm{~kg} / \mathrm{m} \mathrm{sec}^{3}$, buoyancy production term included in the $\mathrm{k}$ equation,

$-P_{k \varepsilon}, \mathrm{kg} / \mathrm{m} \mathrm{sec}^{3}$, buoyancy production term included in the $\varepsilon$ equation,

$-P_{k b}$ and $P_{\epsilon b}$, - represent the influence of the buoyancy forces,

$-U_{i}, U_{j}, U_{k}, \mathrm{~m} / \mathrm{sec}$, vector of velocity,

$-P_{k}, \mathrm{~kg} / \mathrm{m} \mathrm{sec}^{3}$, shear production of turbulence,

$-\mathrm{R}_{\mathrm{e}, \mathrm{L}}$, , Reynolds Number,

$-U, \mathrm{~m} / \mathrm{sec}$, vector of velocity,

$-L, \mathrm{~m}$, geometric characteristic,

$-\mathrm{x}, \mathrm{m}$, width,

$-\mathrm{d}, \mathrm{m}$, diameter,

$-\mathrm{d}_{\mathrm{h}}, \mathrm{m}$, diameter.

\section{References}

[1] S. B. Genić, B. M. Jaćimović, D.N. Mandić, D. Petrović, "Experimental determination of fouling factor on plate heat exchangers in district heating system," Energy and Buildings, vol. 50, pp. 204-211, 2012.

[2] I. A. Stogiannisa, S. V. Paras, O. P. Arsenyevab, P. O. Kapustenkob, "CFD Modeling of Hydrodynamics and Heat Transfer in Channels of a PHE," Chemical Engineering Transactions, vol. 35, 2013.

[3] V. Patil, H. Manjunath, B. Kusammanavar, "Validation Of Plate Heat Exchanger Design Using CFD," International Journal of Mechanical Engineering and Robotics Research, vol. 2, no. 4, 2013.

[4] M. V. Bhatia, P. N. Cheremisinoff, Heat Transfer Equipment. Technomic Publishing, Lancaster, 1980.

[5] H. Kumar, "The Plate Heat Exchanger: Construction and Design," 1st National Conference on Heat Transfer, Leeds, 1984.

[6] J. Kerner, "Plate heat exchangers: avoiding common misconceptions," Chemical Engineering, vol. 116, no. 2, pp. 40-43, 2009.

[7] ANSYS Introduction to CFD Analysis, Introductory FLUENT Notes, FLUENT v 6.3, December 2006.

[8] D. Mandic, "CFD modeling of hydrodynamic phenomena and heat transfer in channels of plate heat exchangers," 4th International Conference of Fluid Flow, Heat and Mass Transfer (FFHMT'17,) Toronto, Canada, 2017. 